\title{
Acid Stable Yeast Cell-Associated Tannase with High Capability in Gallated Catechin Biotransformation
}

\author{
Nalapat Leangnim ${ }^{1,2}$, Jakkrit Aisara ${ }^{1,2}$, Kridsada Unban ${ }^{3,4}$, Chartchai Khanongnuch ${ }^{3,4}$ (D) \\ and Apinun Kanpiengjai ${ }^{2,4, * \mathbb{D}}$ \\ 1 Graduate Program in Biotechnology, The Graduate School, Chiang Mai University, \\ Chiang Mai 50200, Thailand; nalapat_1@cmu.ac.th (N.L.); jakkrit_ai@cmu.ac.th (J.A.) \\ 2 Department of Chemistry, Division of Biochemistry and Biochemical Technology, Faculty of Science, \\ Chiang Mai University, Chiang Mai 50200, Thailand \\ 3 Division of Biotechnology, School of Agro-Industry, Faculty of Agro-Industry, Chiang Mai University, \\ Chiang Mai 50100, Thailand; kridsada_u@cmu.ac.th (K.U.); chartchai.k@cmu.ac.th (C.K.) \\ 4 Research Center for Multidisciplinary Approaches to Miang, Chiang Mai University, \\ Chiang Mai 50200, Thailand \\ * Correspondence: ak.apinun@gmail.com; Tel.: +66-53-943341-5 (ext. 118)
}

Citation: Leangnim, N.; Aisara, J.; Unban, K.; Khanongnuch, C.;

Kanpiengjai, A. Acid Stable Yeast

Cell-Associated Tannase with High Capability in Gallated Catechin Biotransformation. Microorganisms 2021, 9, 1418. https://doi.org/ 10.3390/microorganisms 9071418

Academic Editor: Benedetta Turchetti

Received: 26 May 2021

Accepted: 29 June 2021

Published: 30 June 2021

Publisher's Note: MDPI stays neutral with regard to jurisdictional claims in published maps and institutional affiliations.

Copyright: (C) 2021 by the authors. Licensee MDPI, Basel, Switzerland. This article is an open access article distributed under the terms and conditions of the Creative Commons Attribution (CC BY) license (https:/ / creativecommons.org/licenses/by/ $4.0 /)$.

\begin{abstract}
Previously, nine tannin-tolerant and tannase-producing yeasts were isolated from Miang; all produced cell-associated tannase (CAT) during growth in tannin substrate. Among which, only CAT from Sporidiobolus ruineniae showed better stability than its purified form. Yet, it is of particular interest to directly characterize CATs from the latter yeasts. In this study, four CATs from yeasts, namely Cyberlindnera rhodanensis A22.3, Candida sp. A39.3, Debaryomyces hansenii A45.1, and Cy. rhodanensis A45.3 were characterized. The results indicate that all CATs were produced within the same production yield $(11 \mathrm{mU} / \mathrm{mL})$. Most CATs exhibited similar $\mathrm{pH}$ and temperature optima and stabilities, except for CAT from Cy. rhodanensis A22.3. This CAT was assigned as acid-stable tannase due to its unusual optimum $\mathrm{pH}$ of 2.0 with $\mathrm{pH}$ stability and half-life thermostability in the range of $\mathrm{pH}$ 2.0-4.0, and $70{ }^{\circ} \mathrm{C}$, respectively. All CATs demonstrated high substrate specificity toward epigallocatechin gallate and epicatechin gallate, thus forming epigallocatechin and epicatechin, respectively. Moreover, they showed operational stability to repeated use for up to five cycles without loss of the initial activity. Therefore, CATs from these yeasts could be useful for the extraction and biotransformation of tea catechins and related applications.
\end{abstract}

Keywords: cell-associated tannase; tannase; yeast; tannins; catechin; miang; tea

\section{Introduction}

Tannins are naturally found in plant materials as water-soluble polyphenols with varying molecular weight [1]. They have been classified into three categories including hydrolysable tannins, condensed tannins, and complex tannins. The latter ones are an intermediate group that share a structure combination between hydrolysable tannins and condensed tannins. To form complex tannins, catechin or epicatechin units are linked via glycosidic linkage to a gallotannin or an ellagitannin unit, thus commonly referred to as catechin tannins, the form that is generally found in tea leaves and tropical shrub legumes [2]. Either condensed or complex tannins are considered microbial inhibitors as they resist microbial attacks and are toxic to a variety of microorganisms [3]. In addition, catechin tannins are responsible for the astringent and bitter tastes of tea leaves [4].

Tannin acyl hydrolase (EC 3.1.1.20) is commonly known as tannase, an enzyme that catalyzes the hydrolysis of ester bonds present in gallotannin, complex tannins, and gallate esters to release gallic acid. To date, fungi are the major source of microbial tannase, particularly Aspergillus sp. and Penicillium sp. Bacteria are the second major source of tannase [5], whereas only a few yeasts have been reported to produce tannase, including Candida 
sp. [6], Aureobasidium melanogenum [7], Blastobotrys (Arxula) adeninivorans [8], Kluyveromyces marxianus [9], Sporidiobolus ruineniae [10], and Rhodosporidium diobovatum [11]. Tannases are widely used in various industrial applications including gallic acid production, instant tea production, beer and juice clarification, and effluent treatment [2]. Not only free tannases were industrially applied, but also immobilized enzymes were trialed to reduce some processes and operating costs associated with the production. Immobilized enzymes provide a number of advantages such as an easy separation of the enzymes, a reduction in the cost of downstream processing, the multiple use of the enzymes (recycling), and a better stability toward hazardous conditions [12].

In our previous research study, nine yeast strains isolated from Miang indicated as tannin-tolerant and tannase-producing yeasts belonging to four different species, namely Cyberlindnera rhodanensis (strains A22.3, and A45.3), Debaryomyces hansenii (strains A28.1, A28.2, A42, A45.1 and A46), Candida sp. A39.3, and Sporidiobolus ruineniae A45.2 [13]. They have been confirmed to produce tannase, which is translocated and immobilized onto their cell wall. Yet, these tannases are classified as cell-associated tannases (CATs). A previous study revealed that CAT of S. ruineniae A45.2 is active and more stable toward pH and temperature changes when it occurs on the cell form compared to the free form. In addition, its steady-state kinetic constants, particularly $K_{\mathrm{m}}$, were not significantly different to those of the purified enzyme [10].

Miang is a fermented food product prepared from the tea leaves of Camellia sinensis var. assamica and is traditionally produced in the mountainous areas of northern Thailand. It has a long history that is indicative of a sociocultural relationship with northern Thai people. Unlike other types of tea, Miang is a unique product that is known as chewing tea or eating tea, but it has become less popular among younger generations [14]. The ethnic roots of the Miang production process in northern Thailand is a potential source of a number of health-related bioactive compounds [15-17], specifically tea catechins which continue to attract research interest. However, the Miang production process must be conserved and/or develop to produce a more acceptable product for younger generations.

The refinement of Miang tea products can be considered a way of conserving the local wisdom of northern Thai people. To make the product unique and different from other tea products, the release of the bioactive compounds in Miang tea infusion should be further developed and promoted. Tannase has been purposed as the potential key in liberating various bioactive compounds, particularly epigallocatechin gallate (EGCG) and epicatechin gallate (ECG). Therefore, the research challenge of this work is to develop an acceptable Miang tea product that is similar in popularity to Taiwanese tea and Japanese green tea. It is expected that the developed Miang tea would be more acceptable by younger generations while providing various health benefits.

In this context, we characterized the enzyme properties of the remaining CATs from four representative yeast species including Cy. rhodanensis A22.3, Cy. rhodanensis A45.3, D. hansenii A45.1, and Candida sp. A39.3. Additionally, we demonstrated their applicable features.

\section{Materials and Methods}

\subsection{Chemicals and Culture Media}

High-performance liquid chromatography (HPLC) grade EGCG, ECG, epigallocatechin (EGC), epicatechin (EC), and gallic acid (GA) were purchased from Sigma-Aldrich (St. Louis, MO, USA). Tannic acid, methyl gallate, and propyl gallate were of analytical grade and purchased from Sigma-Aldrich. All chemicals used for buffer preparation, cations, and organic solvents were of analytical grade and obtained from RCI Labscan (Bangkok, Thailand). The medium ingredients used in this study, such as agar, yeast extract, peptone, and malt extract, were purchased from HiMedia (Nashik, India). 


\subsection{Microorganisms and Culture Conditions}

The microorganisms used were obtained from our previous studies [13] and included Cyberlindnera rhodanensis A22.3, Candida sp. A39.3, Debaryomyces hansenii A45.1, and Cy. rhodanensis A45.3. All yeast strains were grown on yeast-malt agar (YMA) (3 g/L yeast extract, $3 \mathrm{~g} / \mathrm{L}$ malt extract, $10 \mathrm{~g} / \mathrm{L}$ glucose, $30 \mathrm{~g} / \mathrm{L}$ agar) supplemented with $1.0 \%(\mathrm{w} / \mathrm{v})$ filter sterile tannic acid at $30{ }^{\circ} \mathrm{C}$ for $24-48 \mathrm{~h}$. For inoculum preparation, a single colony of each yeast strain was spiked in yeast-malt broth (YMB) and incubated at $30^{\circ} \mathrm{C}$ on a 150 -rpm rotary shaker for $24 \mathrm{~h}$ or until the culture reached a maximal optical density at $600 \mathrm{~nm}$ $\left(\mathrm{OD}_{600}\right)$ of 8-9. A $10 \%(\mathrm{v} / \mathrm{v})$ inoculum size was used for cultivation in all experiments.

\subsection{Effect of Temperature on Growth of Tannin-Tolerant Yeasts}

Four strains of yeasts were grown in YMB at $30,37,39,42$, and $45^{\circ} \mathrm{C}$ on a 150 -rpm rotary shaker. After $24 \mathrm{~h}$ of cultivation, for each culture, turbidity was measured at $600 \mathrm{~nm}$.

\subsection{Production of CAT from Tannin-Tolerant Yeasts}

Seed inoculum of $10 \%(\mathrm{v} / \mathrm{v})$ was transferred to a $250-\mathrm{mL}$ Erlenmeyer flask containing $50 \mathrm{~mL}$ YMB supplemented with $5 \mathrm{~g} / \mathrm{L}$ tannic acid. The incubation was carried out on a 150-rpm rotary shaker at $30{ }^{\circ} \mathrm{C}$ for $24 \mathrm{~h}$. Samples were taken in intervals to determine viable cells by the spread plate technique, released gallic acid, and CAT activity [10].

\subsection{CAT Preparation}

To prepare cells for CAT activity assay, the culture was centrifuged at 12,000 rpm at $4{ }^{\circ} \mathrm{C}$ for $5 \mathrm{~min}$. The supernatant was collected for analysis of gallic acid. Accordingly, the cell pellet was collected and washed twice with $20 \mathrm{mM}$ sodium phosphate buffer $\mathrm{pH} 6.5$ supplemented with $0.1 \%(\mathrm{v} / \mathrm{v})$ triton X-100 in order to remove any gallic acid attached to the yeast cell wall. Subsequently, the obtained cells were resuspended in $100 \mathrm{mM}$ sodium phosphate buffer $\mathrm{pH} 6.5$ prior to being used as CAT. Here, triton X-100 played an important role in the removal of gallic acid that had been generated into the culture medium. This was likely caused by the enzymatic degradation of tannic acid. A part of the generated gallic acid was then attached to the yeast cell wall, thus interfering with enzyme activity assay and biochemical characterization.

\subsection{Assay of CAT Activity and Determination of Gallic Acid}

The CAT activity was determined according to a previous report [10], with a slight modification. Briefly, $50 \mu \mathrm{L}$ of yeast cell suspension was mixed with $50 \mu \mathrm{L}$ substrate (12.5 mM methyl gallate in $100 \mathrm{mM}$ sodium phosphate buffer $\mathrm{pH}$ 6.5). The reaction was carried out at $37^{\circ} \mathrm{C}$ for $20 \mathrm{~min}$. Then, $60 \mu \mathrm{L}$ of $0.667 \%(\mathrm{w} / \mathrm{v})$ methanolic rhodanine was added into the reaction mixture to stop the reaction and to detect the release of gallic acid from tannic acid. After $5 \mathrm{~min}$ of incubation at room temperature $\left(25^{\circ} \mathrm{C}\right)$, the pinkish purple color was visualized by adding $40 \mu \mathrm{L}$ of $0.5 \mathrm{M} \mathrm{KOH}$, and the mixture was left at room temperature for $5 \mathrm{~min}$. Finally, $800 \mu \mathrm{L}$ of distilled water was added. The mixture was vigorously mixed and centrifuged at 12,000 rpm for $2 \mathrm{~min}$ to remove the cell pellet. The clear supernatant was then measured at an absorbance of $520 \mathrm{~nm}$. One unit of CAT was defined as the release of $1 \mu \mathrm{mol}$ of gallic acid in $1 \mathrm{~min}$ under the assay conditions. For characterization, CAT activity was initially set up to approximately $36 \mathrm{mU} / \mathrm{mL}$ prior to conducting the experiments.

\subsection{Effect of $\mathrm{pH}$ on CAT Activity and Stability}

To investigate the optimal $\mathrm{pH}$ of CATs, the enzyme was assayed under the standard assay conditions, but the $\mathrm{pH}$ values varied from 1.0 to 9.0, depending on various buffers at $100 \mathrm{mM}$. Potassium hydroxide-hydrochloric acid was used for $\mathrm{pH}$ values ranging from $1.0-2.5$, citrate-phosphate buffer was used for $\mathrm{pH}$ values between 3.0 and 6.0, and sodium phosphate buffer and Tris-hydrochloric acid were used for $\mathrm{pH}$ values ranging from 6.0-8.0 and 8.0-9.0, respectively. The $\mathrm{pH}$ value that gave the maximal CAT activity was set as $100 \%$ 
relative activity. For the determination of $\mathrm{pH}$ stability, $\mathrm{CAT}$ was incubated at various $\mathrm{pH}$ values ranging from 1.0 to 9.0 (at $20 \mathrm{mM}$ ) at $37^{\circ} \mathrm{C}$ for $6 \mathrm{~h}$. The $\mathrm{pH}$ values were dependent upon the buffer systems as previously described. After the incubation process, residual CAT activity was determined according to the standard assay conditions. The percentage of residual activity was calculated by setting the initial CAT activity to $100 \%$ residual activity.

\subsection{Effect of Temperature on CAT Activity Stability}

To investigate the optimal temperature of CAT, the enzyme was assayed using the standard conditions, but at incubation temperatures of $4,20,30,37,40,45,50,55$, and $60{ }^{\circ} \mathrm{C}$. The temperature that gave the maximal CAT activity was considered as $100 \%$ relative activity. For the determination of thermostability, CAT was incubated at temperatures ranging from $4-90{ }^{\circ} \mathrm{C}$ for $1 \mathrm{~h}$. After that, it was placed in an ice bath for $5 \mathrm{~min}$ prior to determining residual activity according to the standard assay conditions. The percentage residual activity was calculated by setting the initial CAT activity to $100 \%$ residual activity.

\subsection{Effect of Cations on CAT Activity}

The CAT was assayed in the presence of different mono-, di-, and trivalent cations, including $\mathrm{Na}^{+}, \mathrm{K}^{+}, \mathrm{Ba}^{2+}, \mathrm{Ca}^{2+}, \mathrm{Mg}^{2+}, \mathrm{Cu}^{2+}, \mathrm{Mn}^{2+}, \mathrm{Co}^{2+}, \mathrm{Ni}^{2+}, \mathrm{Zn}^{2+}, \mathrm{Al}^{3+}$, and $\mathrm{Fe}^{3+}$. Each cation was set to a final concentration of $5 \mathrm{mM}$ in the reaction mixture. The CAT activity assayed without cation supplementation was set as $100 \%$ relative activity.

\subsection{Effect of Organic Solvents on CAT Stability}

The obtained yeast cell pellet as CAT was resuspended with $20 \%(\mathrm{v} / \mathrm{v})$ of different organic solvents at the final concentration and incubated at $37^{\circ} \mathrm{C}$. After incubation for $30 \mathrm{~min}$, the suspension was centrifuged at $12,000 \mathrm{rpm}$ at $4{ }^{\circ} \mathrm{C}$ for $5 \mathrm{~min}$ in order to remove any organic solvents. The cell pellet was resuspended with $100 \mathrm{mM}$ sodium phosphate buffer $\mathrm{pH}$ 6.5. This was done with the same volume of the organic solvent that was applied prior to determining the residual CAT activity using standard assay conditions. The percentage residual activity was calculated by setting the initial CAT activity to $100 \%$ residual activity.

\subsection{Substrate Specificity}

The CAT activity was assayed with $12.5 \mathrm{mM}$ of different substrates, including methyl gallate (MG), propyl gallate (PG), ECGC, and ECG, under the standard assay conditions. The CAT activity was set as 100\% relative activity when assayed with methyl gallate.

\subsection{Feasible Evaluation for the Biotransformation of Catechin Derivatives}

Only EGCG and ECG were evaluated for their feasibility to form other catechin derivatives. Reaction mixtures between each CAT $(36 \mathrm{mU} / \mathrm{mL})$ and $12.5 \mathrm{mM}$ EGCG or ECG were conducted; incubation was carried out at $37^{\circ} \mathrm{C}$ for $60 \mathrm{~min}$. After that, each reaction mixture was centrifuged at $12,000 \mathrm{rpm}, 4^{\circ} \mathrm{C}$ for $5 \mathrm{~min}$ to remove the cell pellet. The supernatant was filtered through a $0.22-\mu \mathrm{m}$ filter cartridge prior to direct injection into a high-performance liquid chromatograph. The VertiSepTM UPS C18 column with a dimension of $5 \mu \mathrm{m} \times 4.6 \mathrm{~mm}$ ID $\times 150 \mathrm{~mm}$ (Vertical Chromatography Co., Ltd., Bangkok, Thailand) was used for the separation of catechin derivatives; it was equilibrated with a mobile phase consisting of a mixture of $0.05 \%$ phosphoric acid pH 2.4 (phase A) and a mixture of methanol and acetonitrile $(3: 2 \mathrm{v} / \mathrm{v})$ (phase B). The linear gradient dynamics were as follows: phase at a ratio of $10 \%$ solution B and $90 \%$ solution A. The separation was achieved with a linear gradient program as follows: $25 \%$ phase $B$ and $75 \%$ phase A for $15 \mathrm{~min}$, then increase to $60 \%$ phase B and $40 \%$ solution A for $25 \mathrm{~min}$. Flow rate and separation temperature were set up at $1 \mathrm{~mL} / \mathrm{min}, 30^{\circ} \mathrm{C}$, respectively. The catechin derivatives were detected by absorbance at $280 \mathrm{~nm}$. 


\subsection{Operational Stability Determination}

The operational stability of CATs was determined using the standard assay conditions ( $\mathrm{pH} 6.5,37^{\circ} \mathrm{C}$ ), with an incubation time of $20 \mathrm{~min}$ in a repeated batch process. Biomass equivalent to $36 \mathrm{U} / \mathrm{mL}$ of each CAT was incubated with $12.5 \mathrm{mM}$ methyl gallate. After each operation, CAT was centrifuged at $12,000 \mathrm{rpm}, 4{ }^{\circ} \mathrm{C}$, for $5 \mathrm{~min}$ and washed with $20 \mathrm{mM}$ citrate-phosphate buffer $\mathrm{pH}$ 7.0. The resulting CAT was then subsequently used for another batch operation. Gallic acid production was determined for each batch. The initial concentration of gallic acid obtained from the first batch was set to $100 \%$.

\subsection{Statistical Analysis}

Data analysis of the mean values was performed based on a full-factorial complete randomized design (CRD). Briefly, data were subjected to analysis of variance (ANOVA), and multiple comparison tests were performed based on all paired comparisons, using Tukey's HSD test at the 95\% confidence level. All analyses were carried out using the Statistix software version 8.0 (Analytical Software, Tallahassee, FL, USA). A probability value of $p<0.05$ was considered significant.

\section{Results}

\subsection{Effect of Temperature on the Growth of Tannin-Tolerant Yeasts}

Two strains of $C y$. rhodanensis (A22.3 and A45.3) had the same range of growth temperature from $30-45^{\circ} \mathrm{C}$, with an optimal temperature from $30-39^{\circ} \mathrm{C}$. Higher temperatures led to significantly low growth. These results contrasted with those found for Candida sp. A39.3 and D. hansenii A45.1, which had a growth temperature of $30^{\circ} \mathrm{C}$ (Figure 1).

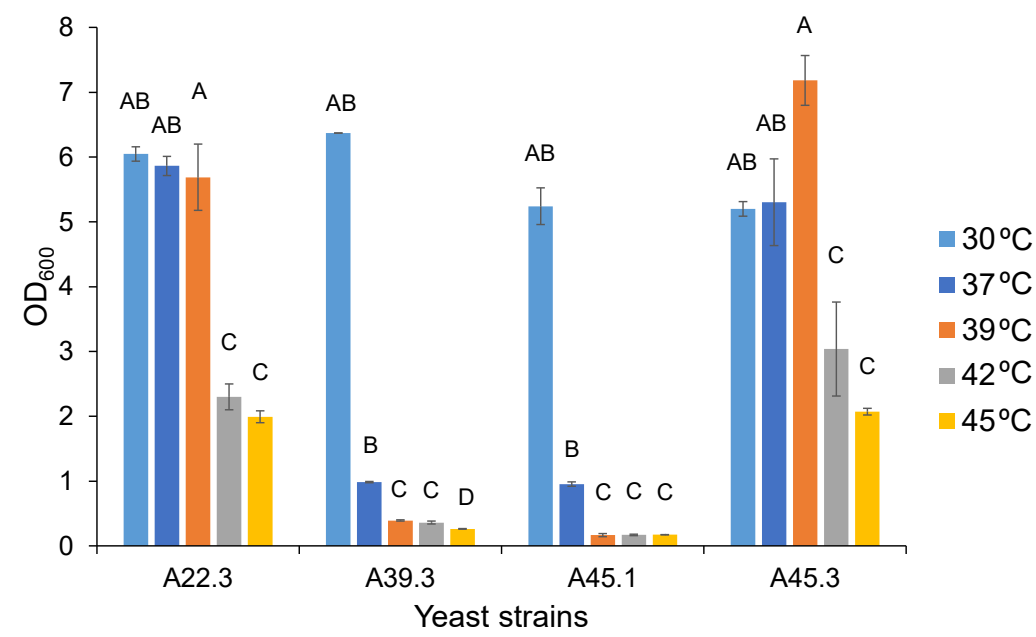

Figure 1. Growth of four CAT-producing yeast strains after being cultivated in YMB at 30, 37, 39, 42, and $45{ }^{\circ} \mathrm{C}$ on a 150 -rpm rotary shaker for $24 \mathrm{~h}$. Different uppercase letters in columns with the same dept indicate significant differences in $\mathrm{OD}_{600}$ values at $p<0.05$. The resulting values represent the mean values of two independent experiments.

\subsection{Profile of CAT Production by Tannin-Tolerant Yeasts}

All yeasts showed a similar growth pattern and increased cell viability, from $10^{9}$ to $10^{10}$ cells $/ \mathrm{mL}$. They had a short lag phase and exponential phase (Figure $\left.2 \mathrm{~A}\right)$. The gallic acid content released into the culture media ranged from 1.0-3.0 g/L, depending on the yeast strain (Figure 2B). Two strains of $C y$. rhodanensis produced high amounts of gallic acid, with a similar production pattern. The gallic acid level was dramatically increased up to approximately $2.4 \mathrm{~g} / \mathrm{L}$ within $18 \mathrm{~h}$ and gradually increased up to $24 \mathrm{~h}$ of the cultivation. Candida sp. A39.3 and D. hansenii A45.1 gradually produced gallic acid, with maximum values of $2.6 \pm 0.3$ and $2.7 \pm 0.3 \mathrm{~g} / \mathrm{L}$ gallic acid, respectively. The tannases produced by the four yeast strains were classified as the cell-associated tannase (CAT). The enzyme 
production profiles slightly differed among the strains, and the overall CAT activities reached the maximum of approximately $11 \mathrm{mU} / \mathrm{mL}$ at $24 \mathrm{~h}$ of cultivation (Figure 2C).

A

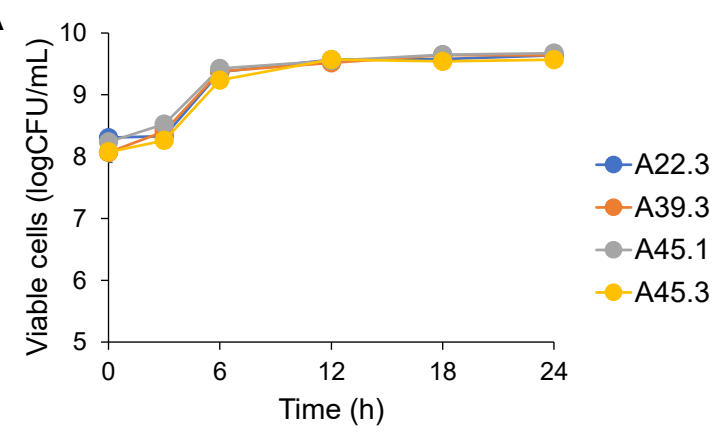

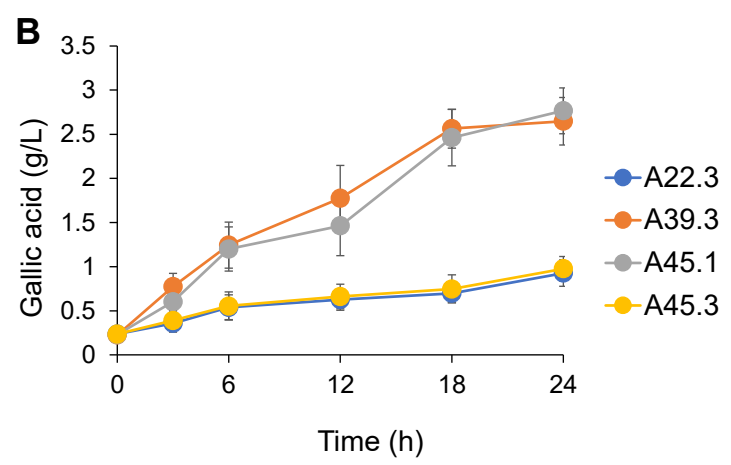

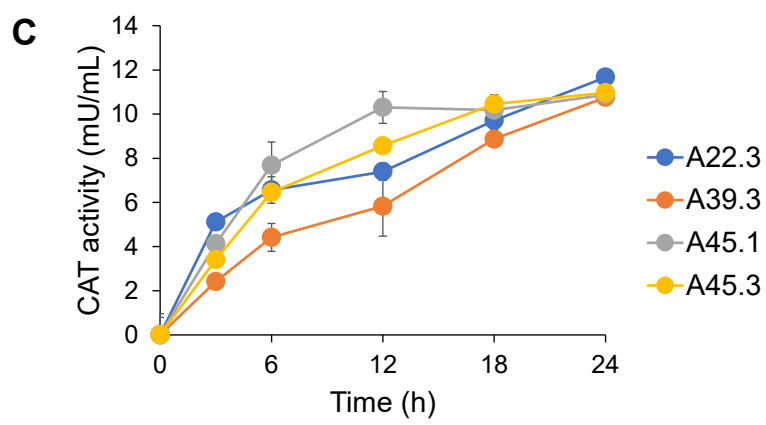

Figure 2. Time course of fermentation for the production of viable cells (A), gallic acid (B), and CAT (C). The conditions were carried in $\mathrm{YMB}$ supplemented with $5 \mathrm{~g} / \mathrm{L}$ tannic acid at $30^{\circ} \mathrm{C}$ on a 150 -rpm rotary shaker for $24 \mathrm{~h}$. The resulting values represent the mean values of two independent experiments.

\subsection{Temperature Optima and Stabilities, and pH Optima and Stabilities of CATs}

The CATs from $C y$. rhodanensis exhibited distinctive differences in optimal temperature and thermostability among strains. The CAT of $C y$. rhodanensis A22.3 showed the highest activity at $50{ }^{\circ} \mathrm{C}$, which is a higher optimal temperature than that for the CAT obtained from $\mathrm{Cy}$. rhodanensis A45.3; it also showed a broader range of temperature optima. The CAT of Candida sp. A39.3 had the same optimal temperature at $30{ }^{\circ} \mathrm{C}$ as that of $C y$. rhodanensis A45.3, whereas the CAT from D. hansenii A45.1 had an optimal temperature of $37^{\circ} \mathrm{C}$ (Figure 3A).

In agreement with the optimal temperature results, the CAT from $\mathrm{Cy}$. rhodanensis A22.3 showed the greatest half-life thermostability at $70{ }^{\circ} \mathrm{C}$, whereas that from $\mathrm{Cy}$. rhodenensis A45.3 exhibited a lower thermostability, with a half-life at $60^{\circ} \mathrm{C}$. The half-life thermostabilities of CATs from Candida sp. A39.3 and D. hansenii were in the same range and were the lowest ones, with values of approximately $50{ }^{\circ} \mathrm{C}$. Notably, CAT obtained from Cy. rhodanensis A22.3 retained its activity at above $80^{\circ} \mathrm{C}$, whereas others were completely inactive at these temperatures (Figure 3B).

The CATs from Cy. rhodanensis A22.3 and Candida sp. A39.3 revealed distinctive profiles of $\mathrm{pH}$ optimum, whereas that from $\mathrm{Cy}$. rhodanensis A45.3 showed a profile similar to that of D. hansenii A45.1. It is remarkable that $C y$. rhodanensis A22.3 produced the CAT that was active at acidic conditions, with an optimum $\mathrm{pH}$ value at 2.0 ; more than $80 \%$ relative activity was detected at $\mathrm{pH} 2.5$ and $\mathrm{pH} 3.0$, respectively. On the other hand, the CAT from Candida sp. A39.3 preferred neutral to alkaline conditions, as its $\mathrm{pH}$ optimum was found at $\mathrm{pH} 7.0$, with more than $80 \%$ relative activity at $\mathrm{pH}$ values up to 9.0. Comparison of the $\mathrm{pH}$ optima between the CATs from D. hansenii A45.1 and Cy. rhodanensis A45.3 revealed that both had similar $\mathrm{pH}$ optima, ranging from $\mathrm{pH}$ 5.0-6.0, but the CAT from $\mathrm{Cy}$. rhodanensis $\mathrm{A} 45.3$ showed a broader range of $\mathrm{pH}$ optima as it was still active, with more than $80 \%$ relative activity, at $\mathrm{pH}$ values ranging from 5.0-9.0 (Figure 3C). 
Not only the $\mathrm{pH}$ optimum but also the $\mathrm{pH}$ stability results revealed that the CAT from $\mathrm{Cy}$. rhodanensis A22.3 was active and stable under acidic conditions. The enzyme was stable and retained its original activity of above $80 \%$ at a pH range of 2.0 to 4.0 under $37^{\circ} \mathrm{C}$ for $6 \mathrm{~h}$. In contrast, the CATs from Candida sp. A39.3, D. hansenii A45.1, and Cy. rhodanensis A45.3 showed a similar profile of $\mathrm{pH}$ stability, with stability between $\mathrm{pH} 4.0$ and 9.0. Remarkably, the CAT from D. hansenii A45.1 was not stable under $\mathrm{pH}$ values below $\mathrm{pH} 4.0$ (Figure 3D).
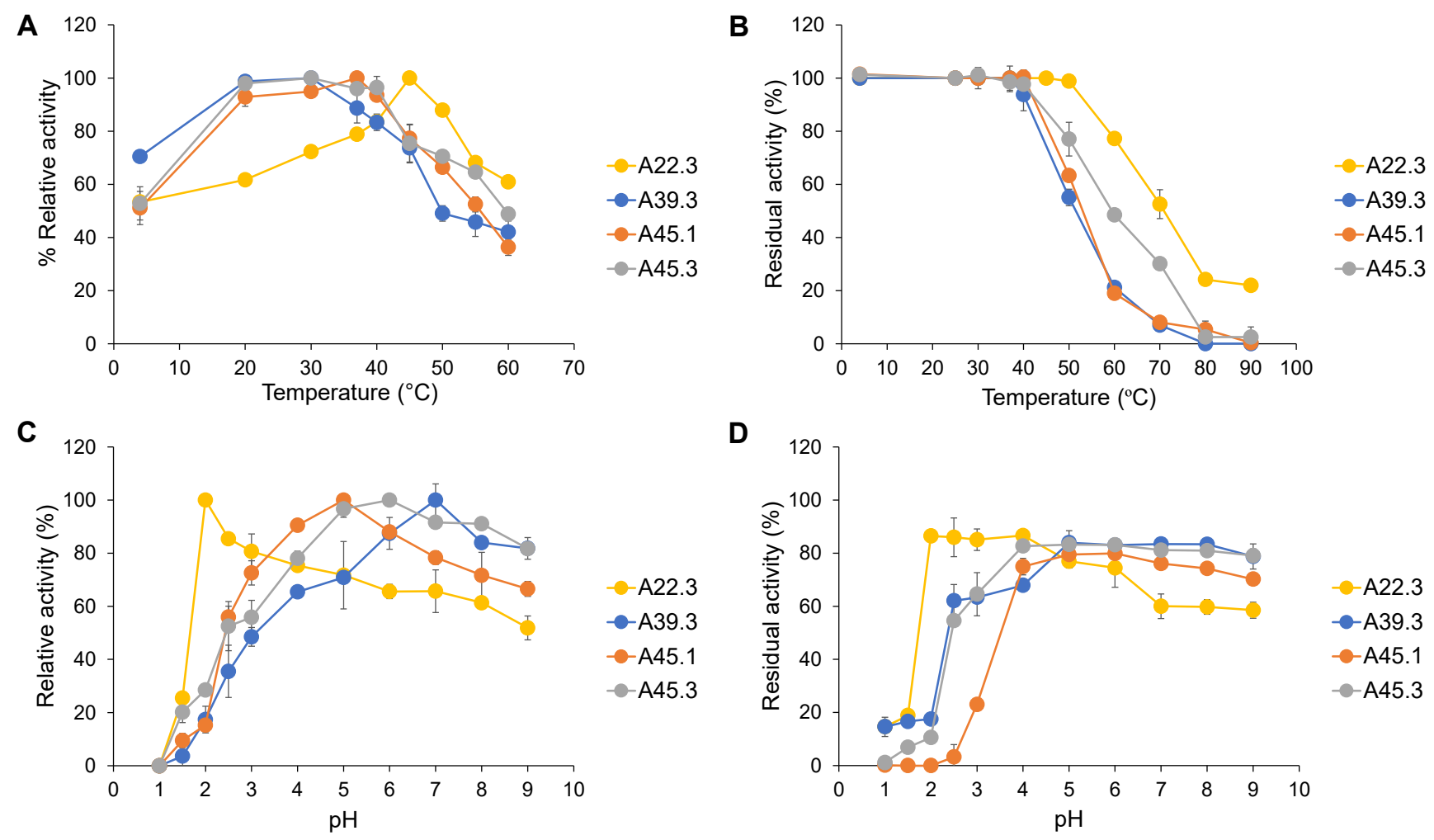

Figure 3. Effect of temperature on CAT activity (A) and stability (B). Effect of pH on CAT activity (C) and stability (D). (A) CAT assay was conducted at different temperatures $\left(4-60{ }^{\circ} \mathrm{C}\right)$ at a $\mathrm{pH}$ of 6.5 for $20 \mathrm{~min}$. The temperature that gave the maximal CAT activity was set as $100 \%$. (B) CAT activity was determined at a pH of 6.5 at $37^{\circ} \mathrm{C}$ for 20 min after being incubated at different temperatures $\left(4-90^{\circ} \mathrm{C}\right)$ for $1 \mathrm{~h}$. The activity without incubation was set to $100 \%$. (C) CAT assay was conducted at different $\mathrm{pH}$ values (1.0-9.0) and at $37^{\circ} \mathrm{C}$ for $20 \mathrm{~min}$. The $\mathrm{pH}$ values that gave the maximal CAT activity was set as $100 \%$. (D) Enzyme activity was determined at a pH of 6.5 and at $37^{\circ} \mathrm{C}$ for $20 \mathrm{~min}$ after being incubated at different $\mathrm{pH}$ values (1.0-9.0) for $6 \mathrm{~h}$. The activity without incubation was set to $100 \%$. The resulting values represent the mean values of two independent experiments.

\subsection{Effects of Cations on CAT Activity}

Most CATs were not affected or partially inhibited by the tested monovalent $\left(\mathrm{Na}^{+}\right.$and $\mathrm{K}^{+}$) and some divalent cations $\left(\mathrm{Ca}^{2+}, \mathrm{Mg}^{2+}\right.$ and $\mathrm{Zn}^{2+}$ ). Divalent cations, including $\mathrm{Mn}^{2+}$, $\mathrm{Co}^{2+}$, and $\mathrm{Ni}^{2+}$, partly enhanced the activities of all CATs. Among the tested cations, $\mathrm{Fe}^{3+}$ was the only trivalent cation that significantly promoted the activities of all CATs, with the highest relative activities ranging from $141.6 \pm 0.0$ to $170.7 \pm 3.2 \%$. On the other hand, $\mathrm{Cu}^{2+}$ was partially inhibited all CATs by approximately $20-40 \%$ compared to the trials without supplementation. Particularly, $\mathrm{Al}^{3+}$ exhibited an inhibitory effect toward all CATs, since the enzymes retained approximately $20-50 \%$ relative activity (Table 1 ). 
Table 1. Effect of cations on CAT activity.

\begin{tabular}{|c|c|c|c|c|}
\hline \multirow{2}{*}{$\begin{array}{l}\text { Cations } \\
(5 \mathrm{mM})\end{array}$} & \multicolumn{4}{|c|}{ Relative Activity (\%) } \\
\hline & $\begin{array}{c}\text { Cy. rhodanensis } \\
\text { A22.3 }\end{array}$ & $\begin{array}{c}\text { Candida sp. } \\
\text { A39.3 }\end{array}$ & $\begin{array}{c}\text { D. hansenii } \\
\text { A45.1 }\end{array}$ & $\begin{array}{c}\text { Cy. rhodanensis } \\
\text { A45.3 }\end{array}$ \\
\hline $\mathrm{Na}^{+}$ & $91.3 \pm 4.3^{\mathrm{d}}$ & $97.9 \pm 3.6^{\mathrm{cd}}$ & $105.4 \pm 6.9 \mathrm{~cd}$ & $98.6 \pm 6.8^{d}$ \\
\hline $\mathrm{K}^{+}$ & $97.6 \pm 4.5^{\mathrm{cd}}$ & $102.1 \pm 3.2^{\mathrm{cd}}$ & $96.2 \pm 2.3^{\mathrm{de}}$ & $88.9 \pm 2.8^{\text {de }}$ \\
\hline $\mathrm{Ba}^{2+}$ & $90.5 \pm 0.4^{\mathrm{d}}$ & $89.7 \pm 4.8^{\mathrm{d}}$ & $84.1 \pm 7.7^{\mathrm{e}}$ & $87.8 \pm 2.7^{\mathrm{de}}$ \\
\hline $\mathrm{Ca}^{2+}$ & $99.5 \pm 0.9 c^{d}$ & $131.9 \pm 2.5^{b}$ & $100.6 \pm 0.1^{\mathrm{cde}}$ & $98.0 \pm 5.6^{\mathrm{d}}$ \\
\hline $\mathrm{Mg}^{2+}$ & $102.1 \pm 2.5^{\mathrm{cd}}$ & $111.3 \pm 6.0^{\mathrm{c}}$ & $86.9 \pm 1.7 \mathrm{de}$ & $80.7 \pm 1.4^{\mathrm{e}}$ \\
\hline $\mathrm{Cu}^{2+}$ & $70.7 \pm 6.0^{\mathrm{e}}$ & $63.4 \pm 2.2^{\mathrm{e}}$ & $88.2 \pm 1.0$ de & $60.3 \pm 2.4^{f}$ \\
\hline $\mathrm{Mn}^{2+}$ & $118.9 \pm 0.8^{b}$ & $154.1 \pm 5.9^{\mathrm{a}}$ & $139.9 \pm 8.6^{b}$ & $171.8 \pm 5.3^{a}$ \\
\hline $\mathrm{Co}^{2+}$ & $119.5 \pm 1.1^{b}$ & $137.9 \pm 3.1^{b}$ & $117.7 \pm 2.2^{c}$ & $144.1 \pm 0.0^{\mathrm{b}}$ \\
\hline $\mathrm{Ni}^{2+}$ & $119.0 \pm 0.8^{b}$ & $111.9 \pm 1.1^{\mathrm{c}}$ & $100.5 \pm 6.0^{\text {cde }}$ & $128.7 \pm 7.2^{\mathrm{c}}$ \\
\hline $\mathrm{Zn}^{2+}$ & $107.2 \pm 1.5^{b c}$ & $90.5 \pm 1.0^{\mathrm{d}}$ & $94.8 \pm 4.7 \mathrm{de}$ & $102.0 \pm 2.2^{\mathrm{d}}$ \\
\hline $\mathrm{Al}^{3+}$ & $53.5 \pm 0.2^{\mathrm{f}}$ & $36.8 \pm 0.9^{\mathrm{f}}$ & $27.8 \pm 4.0^{\mathrm{f}}$ & $18.2 \pm 2.0^{g}$ \\
\hline $\mathrm{Fe}^{3+}$ & $146.3 \pm 4.7^{\mathrm{a}}$ & $142.5 \pm 4.8^{\mathrm{ab}}$ & $170.7 \pm 3.2^{\mathrm{a}}$ & $141.6 \pm 0.0^{\mathrm{bc}}$ \\
\hline Control & $100.0 \pm 6.8^{\mathrm{cd}}$ & $100.0 \pm 0.3^{\mathrm{cd}}$ & $100.0 \pm 3.1^{\text {cde }}$ & $100.0 \pm 2.1^{\mathrm{d}}$ \\
\hline
\end{tabular}

Different lowercase letters within a column indicate significant differences in CAT activity at $p<0.05$. The resulting values represent the mean values of two independent experiments.

\subsection{Effects of Organic Solvents on Enzyme Stability}

All CATs were not stable when incubated in all tested organic solvents, specifically acetone; however, the residual activities toward each organic solvent differed depending on the CAT-producing yeast strains. The CATs from $C y$. rhodanensis tended to be more stable than those from Candida sp. A39.3 and D. hansenii A45.1. They retained more than $50 \%$ of the original activity after incubation in all tested alcohols. The CAT from Candida sp. A39.3 was more stable in propanol and butanol than that of D. hansenii A45.1 (Table 2).

Table 2. Effects of different organic solvents on CAT stability.

\begin{tabular}{ccccc}
\hline \multirow{2}{*}{ Solvents } & \multicolumn{4}{c}{ Residual Activity (\%) } \\
\cline { 2 - 5 } & $\begin{array}{c}\text { Cy. rhodanensis } \\
\text { A22.3 }\end{array}$ & $\begin{array}{c}\text { Candida sp. } \\
\text { A39.3 }\end{array}$ & $\begin{array}{c}\text { D. } \text { hansenii } \\
\text { A45.1 }\end{array}$ & $\begin{array}{c}\text { Cy. rhodanensis } \\
\text { A45.3 }\end{array}$ \\
\hline Methanol & $64.4 \pm 1.3^{\mathrm{b}}$ & $64.9 \pm 5.6^{\mathrm{bc}}$ & $69.4 \pm 2.3^{\mathrm{b}}$ & $90.5 \pm 3.3^{\mathrm{b}}$ \\
Ethanol & $65.4 \pm 3.9^{\mathrm{b}}$ & $55.7 \pm 1.9^{\mathrm{bc}}$ & $55.4 \pm 3.0^{\mathrm{c}}$ & $79.2 \pm 1.7^{\mathrm{c}}$ \\
Propanol & $49.3 \pm 2.0^{\mathrm{c}}$ & $34.4 \pm 2.5^{\mathrm{d}}$ & $13.4 \pm 1.9^{\mathrm{e}}$ & $52.1 \pm 1.8^{\mathrm{d}}$ \\
Butanol & $62.8 \pm 1.0^{\mathrm{b}}$ & $47.8 \pm 4.4^{\mathrm{cd}}$ & $25.2 \pm 3.2^{\mathrm{d}}$ & $74.4^{\mathrm{b}} \pm 2.3^{\mathrm{c}}$ \\
Acetone & $47.0 \pm 4.0^{\mathrm{c}}$ & $17.4 \pm 1.9^{\mathrm{d}}$ & $10.9 \pm 1.4^{\mathrm{e}}$ & $32.8^{\mathrm{a}} \pm 1.5^{\mathrm{e}}$ \\
Control & $100.0 \pm 1.1^{\mathrm{a}}$ & $100.0 \pm 1.5^{\mathrm{a}}$ & $100.0 \pm 0.7^{\mathrm{a}}$ & $100.0 \pm 1.3^{\mathrm{a}}$ \\
\hline
\end{tabular}

Different lowercase letters within a column indicate significant differences in residual CAT activity at $p<0.05$. The resulting values represent the mean values of two independent experiments.

\subsection{Substrate Specificity and Biotransformation of Catechin Derivatives}

In addition to methyl gallate and propyl gallate, two additional substrates were used to determine the substrate specificity of each CAT. Except for CAT from Cy. rhodanensis A22.3, all CATs showed a lower activity when reacting with propyl gallate. Interestingly, all CATs had a higher specificity toward ECG and EGCG than methyl gallate. Furthermore, all CATs showed the highest substrate specificity with ECG (Table 3). The highest relative activities toward ECG were $141.0 \pm 2.8,185.6 \pm 8.4,290.3 \pm 0.3$, and $201.6 \pm 2.8 \%$ relative activity for Cy. rhodanensis A22.3, Candida sp. A39.3, D. hansenii A45.1, and Cy. rhodanensis A45.3, respectively. Although the CAT activity was calculated based on gallic acid production of the certain catechin substrates, the HPLC results revealed that all CATs reacted with EGCG to generate EGC and gallic acid (GA) in addition to EC and GA from ECG (Figure 4). A small amount of the initial substrates was detected after the end of the incubation period. 
Table 3. Substrate specificity.

\begin{tabular}{ccccc}
\hline \multirow{2}{*}{ Strains } & \multicolumn{4}{c}{ Relative Activity (\%) } \\
\cline { 2 - 5 } & Methyl Gallate & Propyl Gallate & EGCG & ECG \\
\hline Cy. rhodanensis A22.3 & $100.0 \pm 3.1^{\mathrm{b}}$ & $95.5 \pm 4.3^{\mathrm{b}}$ & $139.2 \pm 3.1^{\mathrm{a}}$ & $141.0 \pm 2.8^{\mathrm{a}}$ \\
Candida sp. A39.3 & $100.0 \pm 5.2^{\mathrm{c}}$ & $75.7 \pm 5.5^{\mathrm{d}}$ & $160.3 \pm 2.3^{\mathrm{b}}$ & $185.6 \pm 8.4^{\mathrm{a}}$ \\
D. hansenii A45.1 & $100.0 \pm 5.5^{\mathrm{c}}$ & $73.6 \pm 7.8^{\mathrm{d}}$ & $149.6 \pm 1.0^{\mathrm{b}}$ & $290.3 \pm 0.3^{\mathrm{a}}$ \\
Cy. rhodanensis A45.3 & $100.0 \pm 4.1^{\mathrm{c}}$ & $75.4 \pm 7.5^{\mathrm{d}}$ & $153.7 \pm 5.5^{\mathrm{b}}$ & $201.6 \pm 2.8^{\mathrm{a}}$ \\
\hline
\end{tabular}

Different lowercase letters within a row indicate significant differences in relative CAT activity at $p<0.05$. The resulting values represent the mean values of two independent experiments.

A

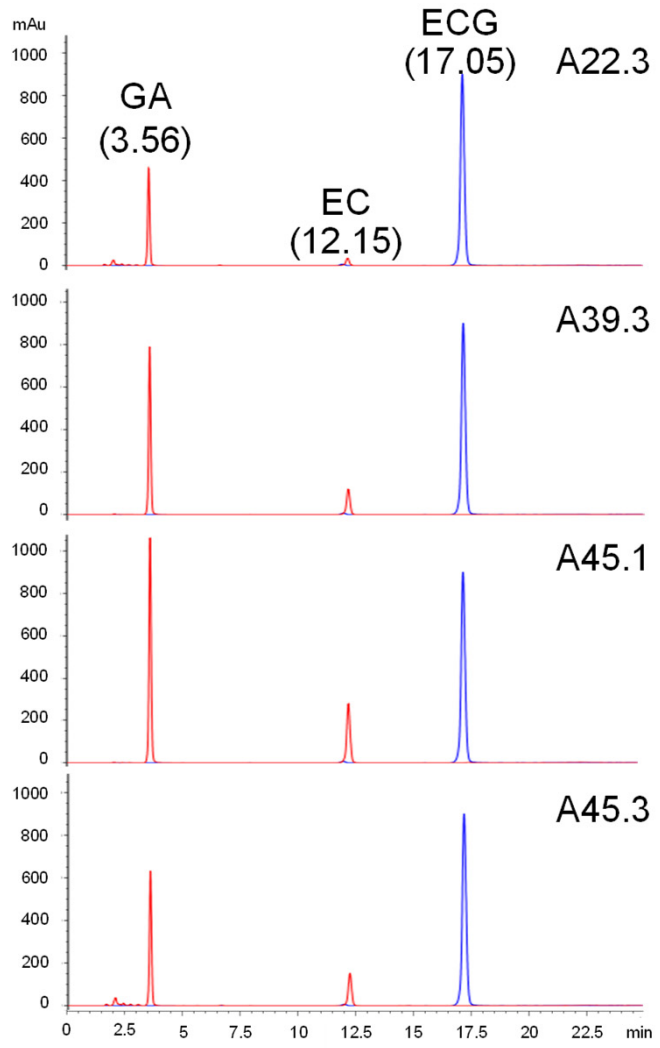

B

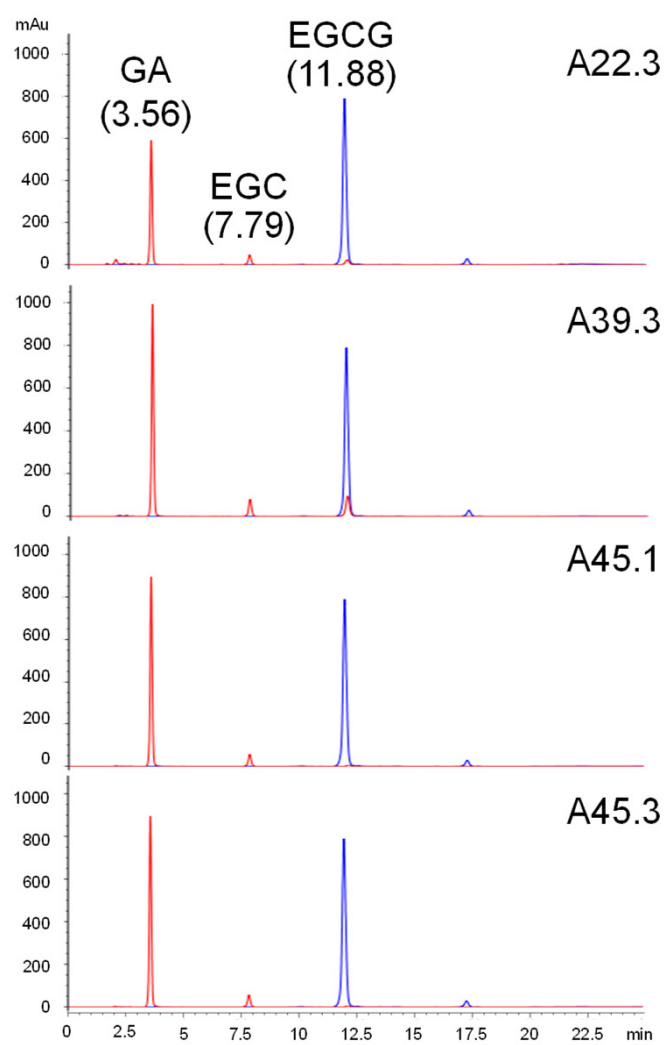

Figure 4. HPLC chromatograms of the biotransformation of ECG (A) and EGCG (B) by different CATs. Blue line represents substrate blank; Red line represents enzyme-substrate reaction.

\subsection{Repeatability of CATs}

All CATs retained almost 100\% relative gallic acid after five runs of gallic acid production from methyl gallate. The relative gallic acid values of all CATs were decreased to $50 \%$ after the CATs were reused for eight runs (Figure 5). 


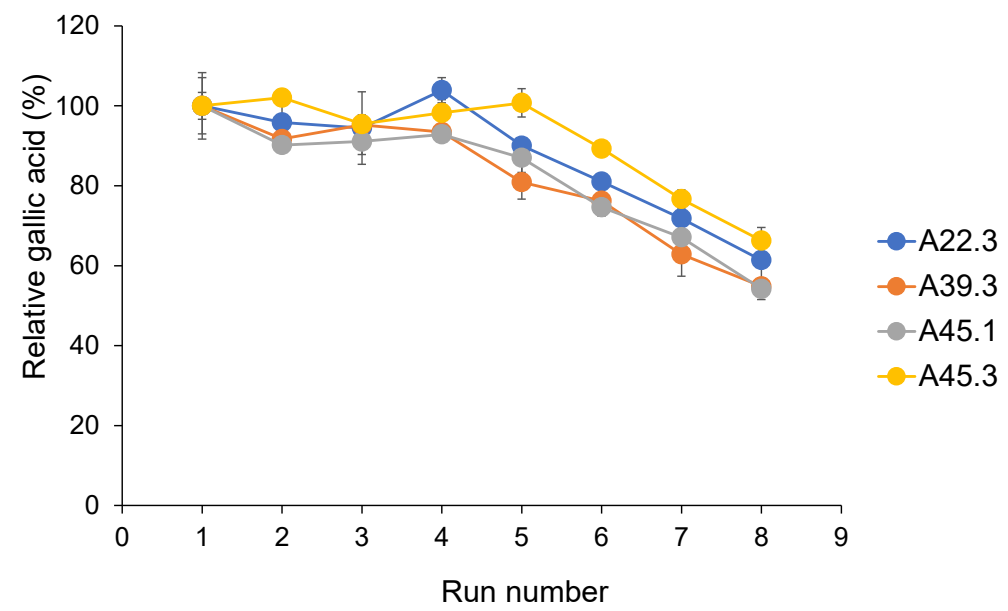

Figure 5. Operational stability of CATs under repeated use. Each CAT was determined using standard assay conditions with an incubation time of $20 \mathrm{~min}$ in a repeated batch process. After that, it was recovered by centrifugation and subsequently used for another batch operation. The initial concentration of gallic acid obtained from the first batch was set to $100 \%$. The resulting values represent the mean values of two independent experiments.

\section{Discussion}

A total of nine tannin-tolerant and tannase-producing yeasts were isolated from Miang, traditionally fermented tea leaves from northern Thailand. They were two strains of $C y$. rhodanensis (strains A22.3, A45.3), five strains of D. hansenii (strains A28.1, A28.2, A42, A45.1 and A46), Candida sp. A39.3 and S. ruineniae A45.2 [10]. In addition to S. ruineniae A45.2, only D. hansenii A45.1 was selected as a representative of D. hansenii since it was able to grow at $30^{\circ} \mathrm{C}$ as the highest growth temperature. Here, the effects of temperature on the growth of four yeast strains were investigated to determine thermotolerant yeasts for further applications, especially probiotic applications, as accomplished in a previous study [18]. Our results show that $C y$. rhodanensis strains are of particular interest due to their high optimum growth temperature of $39^{\circ} \mathrm{C}$; above this temperature, growth was partially limited. In contrast, Candida sp. A39.3 and D. hansenii A45.1 showed optimum growth at $30^{\circ} \mathrm{C}$. One of the most important criteria to evaluate the growth temperature of yeasts is a feasible prediction to achieve an inducible enzyme that may be active and/or tolerant toward high temperatures, as described elsewhere [19]. Tannase is an inducible enzyme produced in the presence of tannins [20], and hence, tannic acid was used as the inducer. When growing in tannic acid, $5 \mathrm{~g} / \mathrm{L}$ tannic acid had no effect on the growth of all yeasts. All yeast strains were able to grow and produce CAT, although the accumulation of gallic acid in their cultures was different, which might be explained by the presence of gallic acid decarboxylase, which generally converts gallic acid to pyrogallol and is active in the presence of oxygen [21]. This result is in accordance with previous reports [7,22]. Yet, it is possible to produce pyrogallol from tannic acid and other form of tannins by CATs from the $C y$. rhodanensis strains.

In this study, all CATs were used for comparative biochemical characterization since it was previously determined that the properties of CAT acted equally or better than the purified enzyme, particularly in terms of enzyme stability [10]. Differences in enzyme properties were found among and within yeast species. The $\mathrm{pH}$ and temperature optima and stabilities of $C y$. rhodanensis A22.3, as well as the substrate specificity, differed from those of $\mathrm{Cy}$. rhodanensis A45.3, whereas other properties, including cation requirement and solvent stability, were similar. Surprisingly, CAT from Cy. rhodanensis A22.3 revealed different biochemical properties compared to other CATs in this research study and to the reported yeast tannases [6,9-11]. No microbial tannase was found to be active and stable at a $\mathrm{pH}$ value of 2.0. Based on the literature, most fungal tannases are generally active at $\mathrm{pH}$ values between 4.0 and 6.0, whereas bacterial tannases are typically active at $\mathrm{pH}$ values 
between 4.0 and 7.0 [5,23], with the exception of lactobacilli tannases such as L. plantarum, L. paraplantarum, and L. pentosus tannases. The reported yeast tannases as well as tannases from Candida sp. A39.3, D. hansenii A45.1, and Cy. rhodanensis A45.3 revealed their $\mathrm{pH}$ optima with values ranging from 4.5 to 7.0 (Table 4 ). Therefore, tannase of Cy. rhodanensis A22.3 can be classified as the first acid-stable tannase.

Table 4. Summary comparison of CAT properties with the reported yeast tannases.

\begin{tabular}{cccccc}
\hline Microorganisms & $\begin{array}{c}\text { Optimal } \\
\mathbf{p H}\end{array}$ & $\begin{array}{c}\text { Optimal } \\
\text { Temperature }\end{array}$ & pH Stability & $\begin{array}{c}\left(\mathbf{t}_{\mathbf{1} / 2}\right) \\
\text { Thermostability }\end{array}$ & References \\
\hline Candida sp. & 6.0 & $50^{\circ} \mathrm{C}$ & $4.0-8.0$ at $13^{\circ} \mathrm{C}, 16 \mathrm{~h}$ & $60^{\circ} \mathrm{C}, 10 \mathrm{~min}$ & {$[6]$} \\
B. adeninivorans & 7.0 & $40^{\circ} \mathrm{C}$ & $5.0-7.0,10 \mathrm{~min}$ & $\begin{array}{c}\text { Stable at } 30-40 \\
{ }^{\circ} \mathrm{C}, 10 \mathrm{~min}\end{array}$ & {$[8]$} \\
K. marxianus & $4-4.5$ & $35^{\circ} \mathrm{C}$ & $4-5.5$, at $30^{\circ} \mathrm{C}, 30 \mathrm{~min}$ & $70^{\circ} \mathrm{C}, 1 \mathrm{~h}$ & {$[9]$} \\
S. ruineniae A45.2 & 7.0 & $40^{\circ} \mathrm{C}$ & $5.0-9.0$ at $37^{\circ} \mathrm{C}, 6 \mathrm{~h}$ & $75{ }^{\circ} \mathrm{C}, 1 \mathrm{~h}$ & {$[10]$} \\
R. diobovatum & 4.5 & $40^{\circ} \mathrm{C}$ & $4.5-5.5$, at $40{ }^{\circ} \mathrm{C}, 12 \mathrm{~h}$ & $55-60{ }^{\circ} \mathrm{C}, 12 \mathrm{~h}$ & {$[11]$} \\
Cy. rhodanensis A22.3 & 2.0 & $45^{\circ} \mathrm{C}$ & $2.0-4.0$, at $37^{\circ} \mathrm{C}, 6 \mathrm{~h}$ & $70^{\circ} \mathrm{C}, 1 \mathrm{~h}$ & This study \\
Cy. rhodanensis A45.3 & 6.0 & $20-40^{\circ} \mathrm{C}$ & $4.0-9.0$, at $37^{\circ} \mathrm{C}, 6 \mathrm{~h}$ & $60^{\circ} \mathrm{C}, 1 \mathrm{~h}$ & This study \\
Candida sp. A39.3 & 7.0 & $20-30^{\circ} \mathrm{C}$ & $5.0-9.0$, at $37^{\circ} \mathrm{C}, 6 \mathrm{~h}$ & $50^{\circ} \mathrm{C}, 1 \mathrm{~h}$ & This study \\
D. hansenii A45.1 & 5.0 & $20-40^{\circ} \mathrm{C}$ & $4.0-9.0$, at $37^{\circ} \mathrm{C}, 6 \mathrm{~h}$ & $50^{\circ} \mathrm{C}, 1 \mathrm{~h}$ & This study \\
\hline
\end{tabular}

The temperature optima and stabilities of the CATs obtained from this study were in the same range as those reported for other microbial tannases. After fungal tannases, yeasts typically produce tannases that are more active and stable at high temperatures than bacterial tannases [5,23-25].

Cations act as salt and complex ions to preserve tannase conformation or to stabilize the binding of a specific substratum molecule as a cofactor [1] rather than to promote the catalytic reaction of the enzyme. It is believed that the rigid conformation of the enzyme molecule can be maintained by a salt or ion bridge via a cluster of carboxylic groups of the enzyme. On the other hand, transition and heavy metals generally inhibit most tannases (example, $\mathrm{Fe}^{2+}, \mathrm{Fe}^{3+}, \mathrm{Cu}^{2+}$, and $\mathrm{Hg}^{2+}$ ), most likely because of the binding to thiol groups or the interaction with tryptophan residues or the carboxy group of amino acids in the enzyme molecule $[26,27]$.

This evidence is partly in agreement with the results of this study since $\mathrm{Fe}^{3+}$ significantly enhanced the activity of all CATs, in contrast to $\mathrm{Al}^{3+}$, whereas $\mathrm{Cu}^{2+}$ partially inhibited all CATs. Similar results have been found for yeast tannases, namely $S$. ruineniae and $R$. diobovatum $[10,11]$. In a previous study, $\mathrm{Cu}^{2+}$ and $\mathrm{Fe}^{3+}$ promoted the activity of tannase from K. marxianus [9], whereas both showed an inhibitory effect on tannase from $B$. adeninivorans [8]. It has been suggested that tryptophan, which is located at the catalytic site of tannase, is highly sensitive to salt interaction and the microenvironment of the enzyme and thus directly affects tannase activity [28].

The protic solvents may facilitate substrate availability of the active site of tannase and enhance enzyme activity at the same time. They can absorb the essential water molecule from the enzyme, which in turn reduces tannase activity [26]. In the transesterification process for the production of gallate esters, the reaction is typically initiated in the presence of non-aqueous solvents to enhance substrate availability [25]. Therefore, solvent-tolerant enzymes are required for certain processes. Here, most tannases were partially inhibited by the tested protic solvents, especially acetone, with the exception of tannases from $C y$. rhodanensis A45.3. It is suggested that the solvent tolerance of tannase varies depending on the strains and species.

Interestingly, all CATs showed high activity toward tea catechins, including EGCG and, especially, ECG. Generally, tea catechins are composed of the four main components epicatechin (EC), epigallocatechin (EGC), epicatechin gallate (ECG), and epigallocatechin gallate (EGCG). Moreover, they have their epimer, namely catechin (C), gallocatechin (GC), catechin gallate (CG) and gallocatechin gallate (GCG), respectively. All tea catechins show antioxidant activity and bioavailability, especially when they are in epimer forms [29]. The stoichiometry for EGCG degradation by tannase is formation of EGC and gallic acid, whereas EC and gallic acid are two major products formed by the degradation of ECG [30]. In recent decades, only a yeast $R$. diobovatum Q95 has been reported to produce 
tannase, which is active toward epicatechins [11]; however, its relative activity to catalyze the hydrolyses of EGCG and ECG was lower than that of the tannases reported in this study. The high substrate specificity toward epicatechins can be explained by the source of tannin-tolerant and tannase-producing yeasts, which may be an enrichment material for microorganisms and, at the same time, act as an inducer for tannase production. All CAT-producing yeasts have been isolated from astringent Miang [13] which were produced by fermentation of young tea leaves for up to 4 weeks [14]. The profile of Miang catechins has been described in a previous study. There were dynamic changes in Miang catechin, especially the biotransformation of EGCG to EGC and ECG to EC during the production process [16]. With regard to the substrate specificity results, all CATs could be used for biotransformation [31], antioxidant activity enhancement, and extraction of tea catechins [32], as well as the improvement of the sweet aftertaste of tea products [4]. Regarding the properties of CAT from Cy. rhodanensis A22.3, this is the first report on acidstable tannase from yeast that can be used as a feed additive tannase for the development of feed formulation.

According to the nature of tannases that are produced and linked on the cell wall surface of yeasts, it can be implied that the CATs can be used as an immobilized enzyme, which is insoluble and can easily be separated from the biotransformation process. In addition, the CATs are reusable, suggesting their application in the further extraction and biotransformation of tea catechins as well as in gallic acid and pyrogallol production.

\section{Conclusions}

In conclusion, this study shows the versatile properties of CATs obtained from tannintolerant and tannase-producing yeasts. They can be applied in numerous fields such as food, feed, and pharmaceutical industries. However, these CATs have a high potential in the biotransformation and extraction of tea catechins due to their substrate specificity. In addition, all CATs are likely to be stable and can be used as immobilized enzymes, which will benefit production processes in terms of enzyme recovery and recycling.

Author Contributions: Conceptualization, A.K.; funding acquisition, A.K.; investigation, A.K. and C.K.; methodology, A.K., N.L., K.U. and J.A.; project administration, A.K.; supervision, A.K. and C.K.; writing—original draft, A.K.; writing—review and editing, A.K. and N.L. All authors have read and agreed to the published version of the manuscript.

Funding: This research study was partially funded by Chiang Mai University.

Institutional Review Board Statement: Not applicable.

Informed Consent Statement: Not applicable.

Data Availability Statement: Not applicable.

Acknowledgments: Not applicable.

Conflicts of Interest: The authors declare no conflict of interest.

\section{References}

1. Govindarajan, R.K.; Mathivanan, K.; Khanongnuch, C.; Srinivasan, R.; Unban, K.; Charli Deepak, A.; Al Farraj, D.A.; Mohammed Alarjani, K.; Al Qahtany, F.S. Tannin acyl-hydrolase production by Bacillus subtilis KMS2-2: Purification, characterization, and cytotoxicity studies. J. King Saud Univ. Sci. 2021, 33, 101359. [CrossRef]

2. Dhiman, S.; Mukherjee, G.; Kumar, A.; Mukherjee, P.; Verekar, S.A.; Deshmukh, S.K. Fungal tannase: Recent advances and industrial applications. In Developments in Fungal Biology and Applied Mycology; Satyanarayana, T., Deshmukh, S.K., Johri, B.N., Eds.; Springer Nature: Singapore, 2017; pp. 295-313.

3. Bhat, T.K.; Singh, B.; Sharma, O.P. Microbial degradation of tannins-A current perspective. Biodegradation 1998, 9, $343-357$. [CrossRef] [PubMed]

4. Zhang, Y.-N.; Yin, J.-F.; Chen, J.-X.; Wang, F.; Du, Q.-Z.; Jiang, Y.-W.; Xu, Y.-Q. Improving the sweet aftertaste of green tea infusion with tannase. Food Chem. 2016, 192, 470-476. [CrossRef] [PubMed]

5. Yao, J.; Guo, G.S.; Ren, G.H.; Liu, Y.H. Production, characterization and applications of tannase. J. Mol. Catal. B Enzym. 2014, 101, 137-147. [CrossRef] 
6. Aoki, K.; Shinke, R.; Nishira, H. Purification and some properties of yeast tannase. Agric. Biol. Chem. 1976, 40, 79-85. [CrossRef]

7. Zhang, L.L.; Li, J.; Wang, Y.L.; Liu, S.; Wang, Z.P.; Yu, X.J. Integrated approaches to reveal genes crucial for tannin degradation in Aureobasidium melanogenum T9. Biomolecules 2019, 9, 439. [CrossRef] [PubMed]

8. Böer, E.; Bode, R.; Mock, H.-P.; Piontek, M.; Kunze, G. Atan1p-an extracellular tannase from the dimorphic yeast Arxula adeninivorans: Molecular cloning of the ATAN1 gene and characterization of the recombinant enzyme. Yeast 2009, $26,323-337$. [CrossRef]

9. Mahmoud, A.E.; Fathy, S.A.; Rashad, M.M.; Ezz, M.K.; Mohammed, A.T. Purification and characterization of a novel tannase produced by Kluyveromyces marxianus using olive pomace as solid support, and its promising role in gallic acid production. Int. J. Biol. Macromol. 2018, 107, 2342-2350. [CrossRef]

10. Kanpiengjai, A.; Khanongnuch, C.; Lumyong, S.; Haltrich, D.; Nguyen, T.-H.; Kittibunchakul, S. Co-production of gallic acid and a novel cell-associated tannase by a pigment-producing yeast, Sporidiobolus ruineniae A45.2. Microb. Cell Factories 2020, 19, 95. [CrossRef]

11. Pan, J.; Wang, N.-N.; Yin, X.-J.; Liang, X.-L.; Wang, Z.-P. Characterization of a robust and pH-stable tannase from mangrovederived yeast Rhodosporidium diobovatum Q95. Mar. Drugs 2020, 18, 546. [CrossRef] [PubMed]

12. Basso, A.; Serban, S. Industrial applications of immobilized enzymes-A review. Mol. Catal. 2019, 479, 110607. [CrossRef]

13. Kanpiengjai, A.; Chui-Chai, N.; Chaikaew, S.; Khanongnuch, C. Distribution of tannin-tolerant yeasts isolated from Miang, a traditional fermented tea leaf (Camellia sinensis var. assamica) in northern Thailand. Int. J. Food. Microbiol. 2016, 238, 121-131. [CrossRef] [PubMed]

14. Khanongnuch, C.; Unban, K.; Kanpiengjai, A.; Saenjum, C. Recent research advances and ethno-botanical history of miang, a traditional fermented tea (Camellia sinensis var. assamica) of northern Thailand. J. Ethn. Foods 2017, 4, 135-144. [CrossRef]

15. Unban, K.; Khatthongngam, N.; Shetty, K.; Khanongnuch, C. Nutritional biotransformation in traditional fermented tea (Miang) from north Thailand and its impact on antioxidant and antimicrobial activities. J. Food Sci. Technol. 2019, 56, 2687-2699. [CrossRef]

16. Unban, K.; Khatthongngam, N.; Pattananandecha, T.; Saenjum, C.; Shetty, K.; Khanongnuch, C. Microbial community dynamics during the non-filamentous fungi growth-based fermentation process of miang, a traditional fermented tea of north thailand and their product characterizations. Front. Microbiol. 2020, 11. [CrossRef] [PubMed]

17. Kodchasee, P.; Nain, K.; Abdullahi, A.D.; Unban, K.; Saenjum, C.; Shetty, K.; Khanongnuch, C. Microbial dynamics-linked properties and functional metabolites during Miang fermentation using the filamentous fungi growth-based process. Food Biosci. 2021, 41, 100998. [CrossRef]

18. Kanpiengjai, A.; Khanongnuch, C.; Lumyong, S.; Kummasook, A.; Kittibunchakul, S. Characterization of Sporidiobolus ruineniae A45.2 Cultivated in Tannin Substrate for Use as a Potential Multifunctional Probiotic Yeast in Aquaculture. J. Fungi 2020, 6, 378. [CrossRef]

19. Rigoldi, F.; Donini, S.; Redaelli, A.; Parisini, E.; Gautieri, A. Review: Engineering of thermostable enzymes for industrial applications. APL Bioeng. 2018, 2, 011501. [CrossRef]

20. Srivastava, A.; Kar, R. Characterization and application of tannase produced by Aspergillus niger ITCC 6514.07 on pomegranate rind. Braz. J. Microbiol. 2009, 40, 782-789. [CrossRef]

21. Aguilar-Zárate, P.; Cruz, M.A.; Montañez, J.; Rodríguez-Herrera, R.; Wong-Paz, J.E.; Belmares, R.E.; Aguilar, C.N. Gallic acid production under anaerobicsubmerged fermentation by two bacilli strains. Microb. Cell Factories 2015, 14, 209. [CrossRef]

22. Meier, A.K.; Worch, S.; Böer, E.; Hartmann, A.; Mascher, M.; Marzec, M.; Scholz, U.; Riechen, J.; Baronian, K.; Schauer, F.; et al. Agdc1p-A gallic acid decarboxylase involved in the degradation of tannic acid in the yeast Blastobotrys (Arxula) adeninivorans. Front. Microbiol. 2017, 8. [CrossRef]

23. Dhiman, S.; Mukherjee, G.; Singh, A.K. Recent trends and advancements in microbial tannase-catalyzed biotransformation of tannins: A review. Int. Microbiol. 2018, 21, 175-195. [CrossRef] [PubMed]

24. Ueda, S.; Nomoto, R.; Yoshida, K.-i.; Osawa, R. Comparison of three tannases cloned from closely related lactobacillus species: $L$. plantarum, L. paraplantarum, and L. pentosus. BMC Microbiol. 2014, 14, 87. [CrossRef]

25. Kanpiengjai, A.; Unban, K.; Nguyen, T.-H.; Haltrich, D.; Khanongnuch, C. Expression and biochemical characterization of a new alkaline tannase from Lactobacillus pentosus. Protein Expr. Purif. 2019. [CrossRef] [PubMed]

26. Jana, A.; Maity, C.; Halder, S.K.; Das, A.; Pati, B.R.; Mondal, K.C.; Das Mohapatra, P.K. Structural characterization of thermostable, solvent tolerant, cytosafe tannase from Bacillus subtilis PAB2. Biochem. Eng. J. 2013, 77, 161-170. [CrossRef]

27. Jana, A.; Halder, S.K.; Banerjee, A.; Paul, T.; Pati, B.R.; Mondal, K.C.; Das Mohapatra, P.K. Biosynthesis, structural architecture and biotechnological potential of bacterial tannase: A molecular advancement. Bioresour. Technol. 2014, 157, 327-340. [CrossRef] [PubMed]

28. Ren, B.; Wu, M.; Wang, Q.; Peng, X.; Wen, H.; McKinstry, W.J.; Chen, Q. Crystal structure of tannase from Lactobacillus plantarum. J. Mol. Biol. 2013, 425, 2737-2751. [CrossRef]

29. Xu, J.Z.; Yeung, S.Y.; Chang, Q.; Huang, Y.; Chen, Z.Y. Comparison of antioxidant activity and bioavailability of tea epicatechins with their epimers. Br. J. Nutr. 2004, 91, 873-881. [CrossRef]

30. Fang, X.; Du, M.; Liu, T.; Fang, Q.a.; Liao, Z.; Zhong, Q.; Chen, J.; Meng, X.; Zhou, S.; Wang, J. Changes in the biotransformation of green tea catechins induced by different carbon and nitrogen sources in Aspergillus niger RAF106. Front. Microbiol. 2019, 10. [CrossRef] 
31. Baik, J.H.; Shin, K.-S.; Park, Y.; Yu, K.-W.; Suh, H.J.; Choi, H.-S. Biotransformation of catechin and extraction of active polysaccharide from green tea leaves via simultaneous treatment with tannase and pectinase. J. Sci. Food Agric. 2015, 95, 2337-2344. [CrossRef]

32. Shao, Y.; Zhang, Y.-H.; Zhang, F.; Yang, Q.-M.; Weng, H.-F.; Xiao, Q.; Xiao, A.-F. Thermostable tannase from Aspergillus niger and its application in the enzymatic extraction of green tea. Molecules 2020, 25, 952. [CrossRef] [PubMed] 